\title{
Ear Wash Solution Dosage Form
}

National Cancer Institute

\section{Source}

National Cancer Institute. Ear Wash Solution Dosage Form. NCI Thesaurus. Code C149466.

Liquid single-dose or multidose preparation consisting usually of an aqueous solution with a pH within physiological limits. Ear washes are intended to clean the external auditory meatus. 